\title{
A Contrastive Study of Chinese and English Apologies in Business Communication
}

\author{
Tu Kang \\ Wuhan International Trade University, Hubei, China, 430205
}

Keywords: Business communication; English and Chinese apologies; Contrast

Abstract: The application of apology is very important in cross-cultural communication. It not only represents the English level of apologists, but also reflects the personal accomplishment of apologists. From the cross-cultural perspective, this paper analyses the choice and contextual features of apologies in English and Chinese, and the language forms of apologies in English and Chinese. Then it analyses the causes of the differences under the two cultural backgrounds from four aspects: the differences in the understanding of apologies, the differences in the use frequency of apologies, the influence of social distance on apologies in English and Chinese, and the influence of relative power on apologies in English and Chinese. Suggestions on cross-cultural integration are put forward.

Apology is a complex speech phenomenon, which can be divided into narrow sense and broad sense. In a narrow sense, apology refers to a sentence containing the words "sorry" and "please forgive". Generally speaking, apology is a speech act: when A offends B, apology can be used to maintain B's face and make up for the consequences of offence, thus restoring harmony between $A$ and B (A is the speaker of apology, B is the speaker of apology or "victim" hearer) (Holmes 1990). Apology is also a common politeness language, which is an important reflection of the politeness principle in pragmatics. According to the "face theory" proposed by Brown P. and S. Levine (1987), politeness, as a common social phenomenon in all language groups, is actually a face problem.

Face can be divided into positive face (the need to be accepted, recognized, liked and have common goals with the group) and negative face (the need to be independent, freedom of movement not interfered with, imposed and hindered). When one party's words and deeds threaten the other party's face, it is necessary to alleviate this threat with Face Saving Act. Apology is a face saving act when threatening the other party's face. However, while maintaining and saving the positive face and negative face of the other party, the apologizing party also threatens its positive face.

\section{The strategy of apology}

Many scholars put forward their own unique opinions on apology strategies according to their own observations and experiments. Holstein and Cohen summarized apology strategies into five categories, as shown in the following figure 1: 
(1)Express an apology directly, such as :Sorry, Excuse me.I apologize for

me, Pardon me for....... I regret that........and so on.

(2)Express the speaker's responsibility for offence, such as: My mistake; You're right to be angry; Didn't mean to upset you.

(3)Explain and explain the cause of the offence, and the apologist states to the "victim" the reason why he has caused some "harm" to the other party. Such as: The traffic

(4)Provide compensation, which is a means used by apologists when "injury" and "offence" can be made up. Such as: Payroll for the damage/broken vase.

(5)Commitment will bind oneself, promise or promise not to make mistakes again. When the apologist feels that his offence is serious and he has a strong sense of guilt,

Figure 1 The Strategy of Apology

Among these five strategies, Holstein believes that the first two strategies are more obvious and common apology strategies, and they will appear alone or together in almost all apology actions. The other three are related to specific situations, which may or may not occur as the specific circumstances change. In addition, people can modify the apology language to strengthen or weaken it to a certain extent. For example, I'm very/really sorry. (Really/sorry/sorry) and I'm sorry, but you really shouldn't get insulted by such remarks. Linguist and pragmatists believe that the choice of apology strategies is mainly restricted by social factors according to their research. These social factors include: the social distance between the speaker and the hearer; the relative power between the speaker and the hearer; the severity of offence; and the relative obligation of apology between the speaker and the hearer.

\section{Major Apology Strategies in Business Communication}

Apology in business activities belongs to the behavior of "complaining - apologizing", which usually involves three subjects: the complainer, the apologia and the complaint. Fraser points out that apologies can only happen when two basic conditions are in place. Firstly, the speaker acknowledges responsibility for his own behavior; secondly, because the speaker's own behavior has the consequence of offending the other party, the speaker transmits some regretful message.

Holstein follows Brown's and Blevins's view that apology is a speech act designed to support offended listeners. In foreign trade complaints and claims conversations and correspondence, business people adopt different apology strategies because of the drive of economic interests, the different objects of communication, the depth of friendship between the two parties and the different nature of complaints. However, there are seven main apology strategies.

(1) The person who directly apologizes for the responsibility directly apologizes to the 
complainer, acknowledges his fault and expresses his willingness to make compensation. (2) Indirect apology alleviates the responsibility of the apologist by apologizing to the complainer and acknowledging his fault, but tends to reduce the degree of his fault or provide reasons to show that the fault is not intentional in order to alleviate the responsibility. (3) The person who expressly denies the apology explicitly denies the occurrence of the complaint or denies that he is responsible for the occurrence of the complaint, emphasizing that he knows nothing about the complaint. (4) Implicit denial of apology avoids talking about complaints, considers others, or delays vaguely, and does not give specific answers.(5) Make excuses for the apologist to prove to the complainer that he is not responsible for the complaint. (6) The person who blames others for apologizing blames the third party, or even the complainer himself, to prove his innocence. (7) The apologist who counters the complaint will choose to knock down a rake to complain when he finds that the complaint evidence is insufficient. As shown in Figure 2:

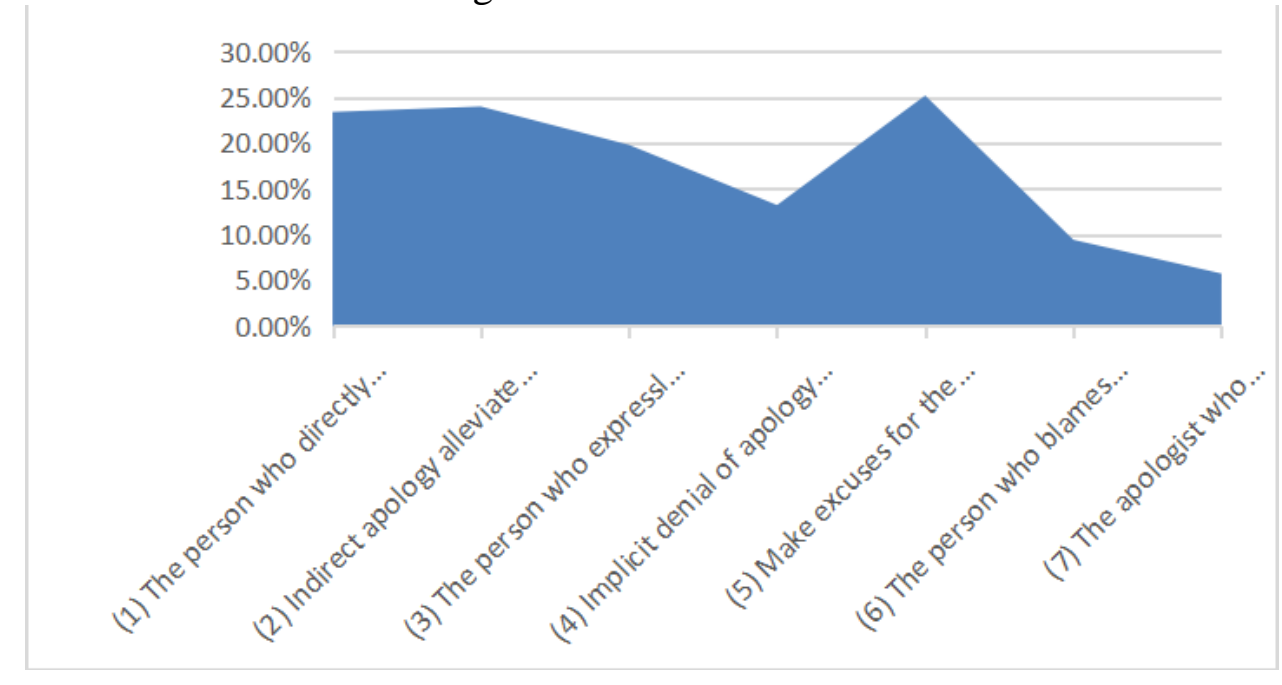

Figure 2 Major Apology Strategies in Business Communication

In reality, due to the comprehensive influence of many factors, apologists may adopt a variety of apology strategies at the same time in order to achieve the best apology effect.

\section{Cultural Contrastive Analysis of Apology Behavior}

\subsection{Influence of power on speech act of apology}

"Power" refers to the social status of the two parties in communication has a clear distance, one party has power over the other, such as superiors to inferiors, elders to young people, employers to employees, etc. To a great extent, the speech of Chinese society is marked by "power", while the speech of Western society is to a large extent the symbol of "equality" relationship. In China, power and hierarchy are more distinct: subordinates should respect their superiors, young people should respect their elders, and superiors are always more authoritative than subordinates. In the West, this hierarchy is not very obvious. The relationship between people tends to be equal, and the relationship between superiors and subordinates may be equal friends.

\subsection{The influence of face on speech act of apology}

In the field of sociology and sociolinguistics, scholars generally define face as "the public intention given by the participants in a communicative event and coordinated with each other", which not only emphasizes the assumptions shared by the communicators about the relationship 
between them, but also emphasizes the coordination of face. In fact, communication not only coordinates with each bother's faces at the time of any communication, but also presumes each bother's faces before it occurs. China has been a country of etiquette since ancient times. Chinese people have more desire to maintain face than Westerners. In daily communication and business activities, Chinese people pay more attention to the maintenance and protection of their own face, intending to win their personal image in the public. It is because of the influence of face that Chinese people do not apologize directly and simply like Westerners in some cases. Therefore, whether it is the frequency or scope of use of apology, Westerners are far higher than Chinese.

For Westerners, apology has become an indispensable part of life. Whoever offends, they apologize, and even if the offence is sometimes negligible, they still say "Forgive me". Most Chinese don't say "I'm sorry". On the one hand, they think that such trifles need not be formally apologized, so they usually use remedial measures instead of apologizing. On the other hand, they think that apologizing will damage the positive face of apologists, and refuse to apologize because of the situation and the maintenance of their positive face. Although Westerners are eager to preserve their own face, they have different concepts of face from Chinese people, so most Westerners use "I m sorry" to apologize in this situation, but British and American people say "I am sorry" is not necessarily something wrong or feel guilty.

\subsection{The impact of values on apology behavior}

Westerner are individualism. They hope that their views will be valued, their values will be affirmed, their interests will not be damaged, and their conflicts will not be condemned by public opinion. Therefore, in the event of conflict, Westerners tend to reduce their responsibility by reducing the severity of the incident, blaming others, questioning the existence of responsibility, or declaring their willingness to compensate for the loss of the other party. The purpose is to maintain their positive face of independence, while restoring the interpersonal relationship with the injured person and restoring the social status of the victim. The values in Chinese traditional culture are collectivism, which attaches great importance to the harmony of the whole. The interests of others and the collective are paramount. The tension and opposition of interpersonal relationships violate social norms and are harmful to the face of both sides.

Therefore, in order to maintain each bother's face and restore harmonious relations, Chinese often adopt a direct and explicit apology strategy to avoid more intense tension and antagonism. Chinese people often use repeated apologies to make the complainer feel the sincerity of the apologia. The apologia not only does not resent the complaint of the complainer, but also praises it. It will further resolve the contradiction between the two sides and help solve the problem. Under the same situation and context, the choice of apology strategy has certain intercultural commonality, but under the influence of different social pragmatic factors (such as relative power, face preservation, values), the choice of apology strategy between China and the West is quite different. In order to achieve better communicative purposes and maintain good relations between trade parties, it is necessary for business staff to be familiar with different cultural backgrounds, master apology strategies and pragmatic meanings in various situations, and make better use of these knowledge.

\section{Conclusion}

Through the comparative analysis of apology behavior habits in English and Chinese cultures, it is found that cultural factors, moral factors, social distance factors and relative power factors play a key role in the application of apology language in cross-cultural communication. By understanding each bother's cross-cultural knowledge, we can effectively grasp the application of apology in cross-cultural context from the perspective of each other, and then improve cross-cultural 
communication ability by learning the application of apology.

\section{References}

[1] Li Li. Statistical Analysis of Differences in Apology Strategies between Chinese and English [J]. Journal of Higher Correspondence, 2001, (4).

[2] Ja Auxin. Intercultural Communication [M]. Shanghai: Foreign Language Education Research Press. 1997.

[3] Bhang Guiana. Speech Acts and Strategies of Apology in Cross-cultural Communication [J]. Journal of Sinkiang Normal University, 2003, 24 (4).

[4] Ian Lei. The Use of Request Strategy in Apology Speech Act [J]. Journal of Hefty University of Technology, 2005, (2).

[5] Chou Urumqi. Pragmatic Analysis of Apology Strategies in Business Activities [J]. Foreign Language Teaching. 2001, (4). 